\title{
PERBEDAAN PERILAKU PHUBBING PADA DEWASA AWAL DALAM SITUASI HUBUNGAN KELUARGA, HUBUNGAN PERTEMANAN, DAN HUBUNGAN PERCINTAAN DI KOTA BUKITTINGGI
}

\author{
Azzati Nur Irawati dan Nurmina \\ Jurusan Psikologi, Universitas Negeri Padang, Sumatera Barat \\ E-mail: irraazzati@gmail.com
}

\begin{abstract}
Abstrak
Penelitian ini bertujuan untuk mengetahui perbedaan perilaku phubbing pada dewasa awal dalam situasi hubungan keluarga, hubungan pertemanan, dan hubungan percintaan di Kota Bukittinggi. Penelitian ini menggunakan desain kuantitatif komparatif. Populasi pada penelitian ini adalah dewasa awal yang berdomisili di Kota Bukittinggi dengan sampel berjumlah 106 orang dan menggunakan teknik purposive sampling. Teknik analisis data menggunakan teknik analisis varians yakni anova satu jalur. Pengumpulan data penelitian ini menggunakan skala phubbing yang diadaptasi oleh (Jihan, 2019). Data deskripsi statistik penelitian menunjukan bahwa skor mean situasi phubbing pada dewasa awal di Kota Bukittinggi lebih besar daripada populasi. Hasil penelitian menunjukkan bahwa nilai $\mathrm{F}=2,448$ dan nilai $p=0,088(p>0,05)$. Sehingga dapat disimpulkan bahwa tidak terdapat perbedaan perilaku phubbing pada dewasa awal dalam situasi hubungan keluarga, hubungan pertemanan, dan hubungan percintaan di Kota Bukittinggi.
\end{abstract}

Kata kunci: phubbing, dewasa awal, situasi hubungan keluarga, situasi hubungan pertemanan, dan situasi hubungan percintaan.

\section{COMPARISON OF PHUBBING BEHAVIOR AMONG YOUNG ADULT IN FAMILY, FRIENDSHIP, AND ROMANTIC RELATIONSHIP SITUATIONS IN BUKITTINGGI CITY}

\begin{abstract}
This study aims to determine differences in phubbing behavior in early adulthood in situations of family relationships, friendships, and romantic relationships in the city of Bukittinggi. This research uses a comparative quantitative design. The population in this study was early adults who lived in the city of Bukittinggi with a sample of 106 people and used a purposive sampling technique. The data analysis technique used variance analysis technique, namely one way ANOVA. The research data collection uses a phubbing scale that was adopted by (Jihan, 2019). The statistical data description of the study shows that the mean score of the phubbing situation in early adulthood in Bukittinggi City is greater than the population. The results showed that the value of $F=2.448$ and the value of Sig or $P=0.088$ (Sig $>0.05)$. So it can be concluded that there are no differences in the behavior of phubbing in early adulthood in situations of family relationships, friendships, and relationships in the city of Bukittinggi.
\end{abstract}

Keywords: phubbing, early adulthood, family relationship situations, friendship situations, and love relationship situations. 


\section{Pendahuluan}

Dunia telah memasuki era baru yaitu era teknologi dan komunikasi. Salah satu kemajuan teknologi yang banyak digunakan adalah telepon genggam, dimana telepon genggam saat ini sudah menjadi bagian terpenting dalam kehidupan manusia. Fasilitas internet yang terdapat dalam telepon genggam dapat memudahkan penggunanya untuk chatting, browsing, game online, mengakses berbagai media sosial seperti instagram, path, facebook, twitter, whatsapp, line dan lainnya (Mulyati \& NRH, 2018). APJII (2019), menunjukkan bahwa pengguna internet di Indonesia tahun 2018 mengalami kenaikan $10,12 \%$ dari tahun sebelumnya. Kenaikan ini mencapai 27 juta pengguna, dimana artinya terdapat 171,17 juta jiwa pengguna internet dari total 264,16 juta jiwa penduduk Indonesia.

Afdal, Alizamar, Ifdil, Ardi, Sukmawati, Zikra, Ilyas, Fikri, Syahputra, \& Hariyani (2018), Menggunakan telepon genggam pada saat berkumpul disuatu tempat atau diruangan, berkomunikasi dua arah dengan orang lain, berada didalam sebuah forum diskusi dan sebagainya merupakan sesuatu yang dianggap normal dan dapat diterima oleh orang-orang. Seiring dengan kemajuan teknologi serta segala kemudahan yang ditawarkan, seseorang sering lupa akan dampak negatif dari penggunaan telepon genggam seperti apa yang disebut dengan perilaku phubbing. Chotpitayasunondh \& Douglas (2016), phubbing merupakan sikap mengacuhkan seseorang kepada lawan bicaranya dengan lebih memilih menggunakan telepon genggam dibandingkan berkomunikasi tatap muka dengan lawan bicaranya.

Afifiyah (2018), munculnya fenomena phubbing yang meluas saat ini membuat banyak masyarakat merasa gelisah. Phubbing juga terjadi saat makan bersama, saat meeting, dan saat seseorang sedang bersama teman atau keluarganya. Selaras dengan pendapat Thaeras (2017), yang mana ketika berada di sebuah restoran terlihat pasangan atau sekumpulan teman yang seharusnya saling berkomunikasi atau berbincang akrab, akan tetapi masih ada diantara mereka yang sibuk dengan telepon genggam meskipun tidak mendesak. Sulis (2016), Baylor University membeberkan bahwa perilaku berlebihan dalam penggunaan telepon genggam berpotensi merusak hubungan dengan lingkungan sekitarnya. Perilaku phubbing dapat merusak hubungan yang dimiliki oleh pengguna telepon genggam dengan seseorang yang hadir dihadapannya (David \& Roberts, 2017). Sementara secara negatif telepon genggam tidak hanya mempengaruhi hubungan interpersonal, tetapi juga kurang memiliki keterampilan komunikasi yang berdampak kepada sulitnya dalam membangun dan mempertahankan kontak mata dengan orang yang berada dihadapannya (Karadag, dkk. 2016).

Karadag, dkk. (2015), melakukan penelitian kepada 401 mahasiswa dengan rentang usia rata-rata 21 tahun. Dalam penelitian ini ditemukan bahwa ponsel, SMS, internet, media sosial dan kecanduan game secara signifikan memiliki efek positif terhadap perilaku phubbing. Chotpitayasunondh \& Douglas (2016), telah melakukan penelitian mengenai perilaku phubbing dengan subjek berjumlah 251 orang dengan rentang usia 18-66 tahun di United Kingdom. Diketahui dari hasil penelitian ini bahwa yang menjadi alasan seseorang menjadi phubber ialah kecanduan telepon genggam. Youarti dan Hidayah (2018), phubber adalah istilah untuk seseorang yang melakukan phubbing. Penelitian phubbing yang dilakukan terhadap anggota keluarga oleh Oduor, dkk. (2016) dengan 20 peserta dari berbagai lokasi di Amerika Utara, dengan usia peserta berkisar antara 20-60 tahun. Hasil menunjukkan bahwa anggota keluarga menjadi frustrasi ketika orang lain melakukan kegiatan yang tidak mendesak di telepon mereka di hadapan orang lain.

Begitu pula penelitian phubbing yang dilakukan dalam hubungan pertemanan. Abeele, Hendrickson, Pollmann, dan Ling (2019), penelitian tehadap 200 peserta dengan mayoritas perempuan 
Perbedaan Perilaku Phubbing Pada Dewasa Awal dalam Situasi Hubungan Keluarga, Hubungan Pertemanan, dan Hubungan Percintaan Di Kota Bukittinggi

Proyeksi Vol. 15 (2) 2020, 141-150

$(\mathrm{N}=153,76,5 \%)$ dengan rata-rata usia perserta adalah 20-49 tahun. Hasil mengungkapkan bahwa perilaku phubbing terjadi pada 62 dari 100 percakapan yang diamati. Dapat disimpulkan bahwa phubbing ditemukan memiliki dampak negatif pada kualitas percakapan (Abeele, dkk. 2019). Roberts dan David (2016), menyusun skala phubbing terhadap 145 partisipan yang berfokus pada orang yang melakukan phubbing (phubber) terhadap pasangan. Hasil penelitian menunjukkan bahwa partner phubbing dapat menciptakan konflik yang akan berpengaruh pada kepuasan hubungan, dan kepuasan hubungan memiliki dampak negatif pada kepuasan hidup yang mengakibatkan seseorang mengalami depresi.

Pada tahun 2019, Al-Saggaf dan Macculloch meneliti tentang phubbing and social relationships. Penelitian ini dilakukan kepada 387 peserta yang sebagian besar berasal dari warga Australia. Penelitiannya mengungkapkan bahwa peserta lebih cenderung untuk melakukan phubbing pada keluarga, teman, dan pasangan, dibandingkan orang ditempat kerja atau orang asing. Berkaitan dengan penelitian phubbing dalam situasi hubungan keluarga yang dilakukan oleh Oduor, dkk. (2016), menunjukan bahwa phubbing dilakukan dalam aktivitas keseharian di rumah seperti di dapur, ruang makan ketika makan bersama, di kamar, ruang tamu disaat berkumpul dengan anggota keluarga, dan bahkan di kamar mandi. Sehingga dari penggunaan telepon genggam yang intens dalam aktivitas keseharian dapat berdampak kepada renggangnya hubungan keluarga yang mana seharusnya dapat meningkatkan kedekatan dan keharmonisan dalam keluarga.

Penelitian Abeele, dkk. (2019) yang berfokus pada phubbing dalam hubungan pertemanan, yang mana ketika seorang teman sibuk dengan telepon genggam mereka ketika sedang berada didalam sebuah forum diskusi, berkumpul di suatu tempat atau berbincang bersama. Hal tersebut akan menghambat terjalinnya sebuah kedekatan yang pada akhirnya membuat teman bicaranya tidak saling mengungkapkan satu sama lain. Krasnova, Abramova, Notter, \& Baumann (2016), temuan tentang phubbing dalam situasi percintaan menunjukkan bahwa phubbing terjadi ketika menghabiskan waktu bersama di rumah, ketika pasangan sedang makan bersama di restoran, dan ketika berjalan-jalan atau berbelanja. Dampak utama dari phubbing pasangan adalah kehilangan perhatian, yang mana dalam hal ini terbukti bahwa penggunaan telepon genggam dihadapan pasangan tidak hanya menimbulkan perasaan kehilangan akan prioritas tetapi juga kecemburuan dan ketidakpuasan hubungan yang pada akhirnya menimbulkan konflik antar pasangan.

Pengguna telepon genggam di Indonesia sendiri pada tahun 2005 hingga 2010 telah menyentuh rentan usia mulai dari 10 sampai 50 tahun atau lebih. Hal tersebut yang menunjukan bahwa penggunaan telepon genggam tidak memberikan batasan usia bagi penggunanya (Lestari, Riana, \& Taftazani, 2015). Salah satu pengguna telepon genggamadalah dewasa awal. Karena maraknya penggunaan telepon genggam di Indonesia membuat peneliti tertarik untuk meneliti perilaku phubbing. Hal ini membuat minat peneliti untuk memahami dan meneliti dalam situasi apa orang lebih mungkin melakukan phubbing, seperti dalam situasi hubungan keluarga, pertemanan dan percintaan. Berdasarkan penjelasan di atas penelitian ini bertujuan untuk mengetahui perbedaan perilaku phubbing pada dewasa awal dalam situasi hubungan keluarga, hubungan pertemanan dan hubungan percintaan di Kota Bukittinggi. 


\section{Metode Penelitian}

Penelitian ini adalah penelitian kuantitatif komparatif. Penelitian komparatif merupakan salah satu jenis penelitian deskriptif yang berusaha mencari jawaban secara mendasar mengenai sebab-akibat, yang sifatnya membandingkan keberadaan satu variabel atau lebih pada dua atau lebih sampel yang berbeda, atau pada waktu yang berbeda (Sugiyono, 2013).

Populasi dalam penelitian ini adalah dewasa awal di Kota Bukittinggi. Menurut Papalia, Old, dan Feldman (2011), dewasa awal ialah seseorang yang berusia 20-40 tahun. Sampel dalam penelitian ini berjumlah 106 orang dewasa awal di Kota Bukittinggi. Penelitian ini menggunakan teknik convenience sampling. Teknik convenience atau accidental sampling merupakan teknik sampling non-probabilitas yang menyeleksi sampel dari orang-orang atau poin-poin yang sudah ada dan cocok. Pengambilan sampling dilakukan berdasarkan kebetulan dapat ditemui pada saat pengumpulan data (Sugiyono, 2013). Adapun ketentuan sampel yang diajukan oleh peneliti di antaranya:
a. Memiliki telepon genggam jenis smartphone.
b. Menggunakan media sosial.
c. Menggunakan telepon genggam minimal 2 jam sehari.
d. Terlibat dalam hubungan keluarga, hubungan pertemanan dan hubungan romantis.

\section{Analisis dan Interpretasi Data}

Pengumpulan data dilakukan dengan menggunakan skala Likert. Peneliti menggunakan skala (Jihan, 2019) yang telah di terjemahkan kedalam bahasa Indonesia dan telah mendapatkan professional judgement, skala yang digunakan yaitu Generic Scale of Phubbing (GSP) oleh Chotpitayasunondh dan Douglas (2018), yang terdiri dari 15 item dan disusun berdasarkan empat aspek yaitu nomophobia, konflik interpersonal, isolasi diri, dan pengakuan masalah. Kemudian skala tersebut di modifikasi oleh peneliti menjadi beberapa alat ukur diantaranya skala phubbing keluarga, skala phubbing pertemanan dan skala phubbing percintaan.

Menurut (Sugiyono, 2013), sebuah alat ukur yang memiliki validitas tinggi memiliki arti bahwa alat ukur tersebut mampu memberikan hasil ukur yang tepat dan sesuai dengan maksud dilakukannya pengukuran tersebut. Menurut (Azwar, 2012), indeks daya diskriminasi item dianggap sudah memuaskan jika nilai $r=0,30$ atau lebih dengan nilai $r$ minimum $r=0,25$. Peneliti melakukan uji coba kepada 94 responden. Berdasarkan hasil yang didapat dari uji coba alat ukur penelitian menunjukkan bahwa aitem untuk pada skala situasi phubbing memiliki daya diskriminasi yang baik. Aitem pada skala situasi phubbing yang berjumlah 45 aitem juga memiliki indeks diskriminasi di atas 0,25.

Setelah dilakukan uji daya diskriminasi aitem, selanjutnya didapatkan nilai koefisien reliabilitas alpha pada skala phubbing dalam situasi keluarga adalah sebesar $(\alpha=0,864)$, skala phubbing dalam situasi pertemanan sebesar $(\alpha=0,870)$, dan skala phubbing dalam situasi percintaan sebesar $(\alpha=$ 0,887). Menurut (Azwar, 2012), semakin tinggi koefisien reliabilitas mendekati angka 1,00 berarti pengukuran reliabilitasnya semakin tinggi. Hal tersebut yang menyatakan bahwa skala situasi phubbing pada uji coba ini memiliki reliabilitas yang tinggi.

Selanjutnya dilakukan uji normalitas. Uji normalitas dilakukan dengan tujuan untuk melihat apakah data penelitian telah berdistribusi normal atau belum. Berdasarkan hasil uji normalitas, data phubbing situasi yang diperoleh telah berdistribusi dengan normal. Tahap berikutnya yang dilakukan ialah uji homogenitas yang bertujuan untuk mengetahui bahwa dua atau lebih kelompok data sampel yang datang dari populasi yang memiliki varians sama (homogen). Tahap terakhir adalah uji hipotesis 
Perbedaan Perilaku Phubbing Pada Dewasa Awal dalam Situasi Hubungan Keluarga, Hubungan Pertemanan, dan Hubungan Percintaan Di Kota Bukittinggi

Proyeksi Vol. 15 (2) 2020, 141-150

dengan tujuan untuk pembuktian hasil analisis data statistik supaya dapat ditarik kesimpulannya yakni untuk melihat apakah terdapat perbedaan perilaku phubbing dalam situasi hubungan keluarga, hubungan pertemanan dan hubungan percintaan.

Dalam melihat perbedaan antara dua variabel yaitu variabel independen (situasi phubbing) dan variabel dependen (perilaku phubbing), teknik analisis data yang digunakan yaitu analisis varian. Analisis varian atau yang biasa dikenal sebagai anava merupakan jenis analisis statistik yang berfungsi untuk menguji perbedaan antara tiga kelompok data atau lebih (Winarsunu, 2007). Data yang diperoleh dari hasil penelitian kemudian diolah menggunakan teknik anova (analisis varians satu jalur).

\section{Hasil Penelitian}

Tabel 1. Deskripsi Subjek Penelitian

\begin{tabular}{lll}
\hline Durasi Penggunaan Telepon Genggam & Frekuensi & Persentase (\%) \\
\hline 2-5 Jam & 24 & $23 \%$ \\
6-10 Jam & 54 & $51 \%$ \\
11-15 Jam & 18 & $17 \%$ \\
16-20 Jam & 10 & $9 \%$ \\
21-24 Jam & - & - \\
\hline Total & $\mathbf{1 0 6}$ & $\mathbf{1 0 0 \%}$ \\
\hline
\end{tabular}

Subjek dalam penelitian ini adalah dewasa awal di Kota Bukittinggi, memiliki telepon genggam, menggunakan media sosial, menggunakan telepon genggam minimal 2 jam sehari, terlibat dalam hubungan romantis, hubungan pertemanan dan hubungan keluarga. Subjek dalam penelitian ini sebanyak 106 orang. Setiap orang diberikan tiga macam alat ukur penelitian, yaitu skala phubbing situasi keluarga, skala phubbing situasi pertemanan, dan skala phubbing situasi percintaan.

Durasi penggunaan telepon genggam didominasi oleh subjek yang menggunakan telepon genggam selama 6-10 jam sebanyak 54 orang (51\%), kemudian diikuti oleh subjek yang menggunakan telepon genggam selama 2-5 jam sebanyak 24 orang (32\%), subjek yang menggunakan telepon genggam selama 11-15 jam sebanyak 18 orang (17\%), subjek yang menggunakan telepon genggam selama 1620 jam sebanyak (9\%), dan tidak ada subjek yang menggunakan telepon genggam selama 16-24 jam.

Tabel 2. Data Deskripsi Statistik Situasi Phubbing

\begin{tabular}{lllllllll}
\hline \multirow{2}{*}{ Situasi Phubbing } & \multicolumn{4}{c}{ Skor Hipotetik } & \multicolumn{4}{c}{ Skor Empirik } \\
\cline { 2 - 9 } & Min & Max & Mean & SD & Min & Max & Mean & SD \\
\hline Phubbing Keluarga & 15 & 60 & 37,5 & 7,5 & 18 & 60 & 39,91 & 9,593 \\
Phubbing Pertemanan & 15 & 60 & 37,5 & 7,5 & 21 & 60 & 40,51 & 10,165 \\
Phubbing Percintaan & 15 & 60 & 37,5 & 7,5 & 23 & 58 & 42,69 & 9,114 \\
\hline
\end{tabular}

Berdasarkan tabel diatas dapat dilihat bahwa mean empirik phubbing keluarga $(39,91)$, phubbing pertemanan $(40,51)$, phubbing percintaan $(42,69)$, sedangkan mean hipotetik pada masing-masing situasi phubbing sebesar $(37,5)$. Data tersebut menunjukan bahwa skor mean empirik situasi phubbing lebih besar daripada mean hipotetik situasi phubbing. Dijelaskan bahwa ketika nilai empirik lebih besar daripada nilai hipotetik hal tersebut menunjukan bahwa secara umum situasi phubbing subjek dalam penelitian ini lebih tinggi daripada populasi pada umumnya. Nilai populasi dapat dilihat dari mean hipotetik, sedangkan nilai pada subjek dapat dilihat dari nilai empirik. Artinya situasi phubbing yang dilakukan pada dewasa awal di Kota Bukittinggi lebih tinggi dari populasi. 
Pengujian normalitas sebaran data menggunakan model one sample kolmogorov smirnov. Uji normalitas dimaksudkan bertujuan untuk mengetahui apakah data variabel yang diteliti berdistribusi normal atau tidak. Berdasarkan hasil perhitungan menggunakan perangkat lunak komputer SPSS Statistics 20 for window, dapat dilihat bahwa phubbing dalam situasi hubungan keluarga memperoleh nilai $\mathrm{K}-\mathrm{SZ}=1,296$ dan nilai $\mathrm{P}=0,069$, phubbing dalam situasi hubungan pertemanan memperoleh nilai $\mathrm{K}-\mathrm{SZ}=1,288$ dan nilai $\mathrm{P}=0,073$, dan phubbing dalam situasi hubungan percintaan memperoleh nilai $\mathrm{K}$ $\mathrm{SZ}=1,006$ dan nilai $\mathrm{P}=0,263$. Jadi sebaran data phubbing berdasarkan pada ketiga situasi tersebut berdistribusi normal sehingga dapat dianalisis dengan statistik parametrik.

Setelah uji normalitas terpenuhi maka tahap selanjutnya yaitu uji homogenitas. Uji homogenitas dilakukan dengan tujuan untuk mengetahui variabel situasi phubbing bersifat homogen atau tidak. Uji homogenitas varians dilakukan dengan menggunakan uji levene's. Hasil uji homogenitas varians diperoleh nilai $F$ sebesar 0,622 dengan $p=0,538(p>0,05)$. Hasil ini menunjukan bahwa asumsi homogen dalam penelitian ini telah terpenuhi.

Tabel 3. Anova

\begin{tabular}{llllll}
\hline \multicolumn{7}{c}{ Situasi Phubbing } \\
\hline Between Groups & Sum of Squares & df & Mean Square & F & Sig. \\
Within Groups & 454,346 & 2 & 227,173 & 2,448 &, 088 \\
Total & 29234,274 & 315 & 92,807 & & \\
\hline
\end{tabular}

Uji hipotesis penelitian bertujuan untuk pemeriksaan batasan atau penolakan taraf signifikan statistik dari koefisien jalur yang dihasilkan. Hasil uji hipotesis menggunakan analisis varians satu jalur. ANOVA digunakan sebagai alat untuk menganalisis dan menguji hipotesis penelitian yang mana bertujuan untuk melihat apakah terdapat perbedaan mean kelompok. Adapun kriteria penilaiannya adalah Ho diterima jika nilai taraf signifikansi (sig>0,05) dan Ho ditolak jika taraf signifikansi $(s i g<0,05)$. Adapun hasil perhitungan ANOVA yang peneliti dapatkan dengan tahap pengujian perbedaan taraf signifikansi diperoleh sebesar Sig=0,088 (Sig >0,05) dengan nilai F sebesar 2,448 yang berati bahwa Ho diterima dan Ha ditolak. Dari hasil tersebut dapat disimpulkan bahwa tidak terdapat perbedaan perilaku phubbing pada dewasa awal dalam situasi hubungan keluarga, hubungan pertemanan dan hubungan percintaan di Kota Bukittinggi.

\section{Pembahasan}

Berdasarkan hasil perhitungan anava satu jalur diperoleh hasil analisis hipotesis alternatif ( $\mathrm{Ha}$ ) pada penelitian ini yang berbunyi terdapat perbedaan perilaku phubbing pada dewasa awal dalam situasi hubungan keluarga, hubungan pertemanan dan hubungan percintaan di Kota Bukittinggi dalam penelitian ini ditolak dan Ho diterima. Skor phubbing keluarga pada dewasa awal di Kota Bukittinggi termasuk dalam kategori tinggi. Hasil penelitian ini didukung oleh penelitian sebelumnya yaitu Oduor, dkk. (2016), dimana perilaku phubbing mempengaruhi hubungan dengan keluarga. Hasil menunjukkan bahwa anggota keluarga menjadi frustrasi ketika orang lain melakukan kegiatan yang tidak mendesak di telepon mereka di hadapan orang lain, kurang keterlibatan antar anggota keluarga. Interaksi yang masuk melalui telepon genggam sering dianggap lebih penting dari pada kegiatan yang mungkin sedang berlangsung.

Skor phubbing dalam situasi pertemanan pada dewasa awal di Kota Bukittinggi juga tergolong tinggi. Hasil penelitian ini didukung oleh penelitian sebelumnya yaitu Abeele, dkk. (2019), dimana 
Perbedaan Perilaku Phubbing Pada Dewasa Awal dalam Situasi Hubungan Keluarga, Hubungan Pertemanan, dan Hubungan Percintaan Di Kota Bukittinggi

Proyeksi Vol. 15 (2) 2020, 141-150

pengalaman teman bicara menyebutkan bahwa percakapan tersebut membosankan atau tidak cukup menarik untuk saling berbagi perhatian satu sama lain. Hasil mengungkapkan bahwa phubbing ditemukan memiliki dampak negatif pada kualitas percakapan (Abeele, dkk. 2019). Skor phubbing percintaan pada dewasa awal di Kota Bukittinggi pun tinggi. Hasil penelitian ini didukung oleh penelitian sebelumnya yaitu Roberts dan David (2016), hasil penelitian menunjukkan bahwa partner phubbing dapat menciptakan konflik yang akan berpengaruh pada kepuasan hubungan, dan kepuasan hubungan memiliki dampak negatif pada kepuasan hidup yang mengakibatkan seseorang mengalami depresi. Partner phubbing pada umumnya terjadi ketika sedang menghabiskan waktu bersama di rumah, ketika sedang makan bersama di restoran, ketika sedang dalam perjalanan di angkutan umum atau di mobil dan ketika berjalan-jalan atau berbelanja (Krasnova, Abramova, Notter, dan Baumann, 2016).

Pada umumnya dewasa awal di Kota Bukittinggi menggunakan telepon genggam lebih dari dua jam dalam sehari. Berdasarkan hasil penelitian, kebanyakan dewasa awal di Kota Bukittinggi menggunakan telepon genggam selama enam sampai sepuluh jam sehari. Hal tersebut mendukung hasil penelitian (Karadag, dkk. 2015) yang menyatakan bahwa $75 \%$ responden menghabiskan waktu dua jam atau lebih di telepon genggam atau internet dalam sehari.Perilaku phubbing dapat merusak hubungan yang dimiliki oleh pengguna telepon genggam dengan seseorang yang hadir dihadapannya (David \& Roberts, 2017).

Ditemukan bahwa phubbing memiliki dampak negatif kepada kepuasan dalam suatu hubungan, kualitas percakapan yang menurun, kepuasan hidup, dan suasana hati yang bermasalah (Al-Saggaf \& Macculloch, 2019). Sementara secara negatif telepon genggam tidak hanya mempengaruhi hubungan interpersonal, tetapi juga kurang memiliki keterampilan komunikasi yang berdampak kepada sulitnya dalam membangun dan mempertahankan kontak mata dengan orang yang berada dihadapannya saat menggunakan telepon genggam, serta kesalahan dalam memahami apa yang dibahas (Karadag, dkk. 2016).

Diperkuat oleh Chotpitayasunondh \& Douglas (2018), salah satu faktor yang membentuk perilaku phubbing yaitu disebabkan karena adanya konflik interpersonal yang terjadi karena phubber lebih memilih untuk memainkan telepon genggamnya dibandingkan melalukan berinteraksi dengan orang disekitarnya. Saat ini kualitas interaksi antar individu menjadi salah satu hal yang cukup memperihatinkan (Chotpitayasunondh dan Douglas, 2016). Hal ini sejalan dengan hasil penelitian, dimana dalam penelitian ini ditemukan bahwa skor situasi phubbing tergolong dalam kategori tinggi. Dijelaskan bahwa ketika nilai empirik lebih besar daripada nilai hipotetik hal tersebut menunjukan bahwa secara umum situasi phubbing subjek dalam penelitian ini lebih tinggi daripada populasi pada umumnya. Berdasarkan penjelasan tersebut peneliti menduga bahwa interaksi antar dewasa awal di Kota Bukittinggi masih kurang terjalin dengan baik.

Faktor yang menyebabkan tidak adanya perbedaan dalam penelitian ini dikarenakan saat ini perilaku phubbing sudah semakin umum dilakukan. Seseorang menggunakan telepon genggam setiap saat dan kepada siapapun (Youarti \& Hidayah, 2018). Hal tersebut dapat dilihat berdasarkan hasil mean empirik dari ketiga situasi tersebut, terlihat bahwa ketiga situasi phubbing memiliki skor mean empirik yang lebih tinggi daripada skor mean hipotetik. Sehingga didapati phubbing pada dewasa awal dalam situasi hubungan keluarga, situasi hubungan pertemanan, dan situasi hubungan percintaan tidak memiliki perbedaan yang signifikan. 
Berdasarkan paparan diatas didapatkan kesimpulan bahwa tidak terlihat perbedaan perilaku phubbing ditinjau dari situasi hubungan keluarga, hubungan pertemanan, dan hubungan percintaan. Karena didapatkan hasil secara umum phubbing yang dilakukan dalam tiga situasi berada pada kategori tinggi dan hampir semua aspek berada pada kategori tinggi juga. Faktor yang mempengaruhi situasi phubbing pada subjek penelitian ini dikarenakan telepon genggam sudah menjadi sebuah kebutuhan, dimana seseorang tidak lagi dapat dipisahkan dengan telepon genggam. Perilaku phubbing kerap dilakukan dalam rangka pemenuhan kebutuhan sosial. Fear of missing out atau perasaan takut ketinggalan jika tidak update dengan berita sehingga keberadaannya kurang diakui melatarbelakangi seseorang dalam berperilaku phubbing (Amelia, dkk, 2019). Selain itu adanya rasa khawatir dianggap "hilang" jika tidak segera merespon pesan yang ada, atau singkatnya memberi late response juga menjadi faktor penyebab perilaku phubbing yang berkaitan dengan kebutuhan seseorang untuk diakui keberadaan sosialnya.

Perilaku phubbing tentu banyak memberi dampak pada diri seseorang. Beberapa subjek pada penelitian Amelia, dkk (2019) menyatakan bahwa mereka merasakan dampak kesehatan fisik seperti mata yang lelah dan kepala yang pusing karena terlalu banyak melihat layar telepon genggamnya. Dalam situasi sosial, tentu tidak semua orang dapat menerima perilaku phubbing. Perasaan tidak suka dan tidak dihargai akan muncul ketika bersama mereka yang merupakan seorang phubber. Seseorang akan merasa bahwa dirinya "tergantikan" oleh smartphone ketika bersama seorang phubber. Perilaku phubbing ini dapat menyebabkan pelakunya menjadi kurang menyadari tentang apa yang terjadi di lingkungan sekitar, kurangnya kemampuan berkomunikasi langsung dan kehilangan kesempatan komunikasi dengan orang baru.

Menurut Youarti dan Hidayah (2018), kehadiran media baru seperti telepon genggam seakan menjadi kebutuhan pokok bagi masyarakat modern. Dengan perkembangan zaman, telepon genggam tidak lagi hanya menjadi pelengkap bagi masyarakat umum akan tetapi sudah menjadi kebutuhan pokok. Hal tersebut memperkuat hasil penelitian yang menyatakan bahwa tidak terdapat perbedaan perilaku phubbing pada dewasa awal dalam situasi hubungan keluarga, hubungan pertemanan dan hubungan percintaan di Kota Bukittinggi.

Individu di usia dewasa awal, terutama di era milenial seperti ini seharusnya dapat lebih mengontrol diri dalam menggunakan smartphone agar tidak mengganggu interaksi interpersonal dalam seharihari. Perilaku phubbing dapat dikurangi dengan melakukan hal sederhana seperti mengheningkan suara dering telepon genggam agar perhatian dapat tetap fokus kepada teman, pasangan atau anggota keluarga yang berada di dekat kita. Mengurangi perilaku phubbing ini dapat membuat orang lain merasa dihargai dan meningkatkan kualitas hubungan diri sendiri dengan orang-orang terdekat.

\section{Simpulan}

Berdasarkan hasil penelitian dan pengujian hipotesis mengenai perbedaan perilaku phubbing pada dewasa awal dalam situasi hubungan keluarga, hubungan pertemanan dan hubungan percintaan di Kota Bukittinggi dapat ditarik kesimpulan sebagai berikut:

1. Berdasarkan hasil penelitian menunjukan bahwa skor phubbing dalam situasi hubungan keluarga, hubungan pertemanan dan hubungan percintaan pada dewasa awal di Kota Bukittinggi tergolong dalam kategori tinggi. 
Perbedaan Perilaku Phubbing Pada Dewasa Awal dalam Situasi Hubungan Keluarga, Hubungan Pertemanan, dan Hubungan Percintaan Di Kota Bukittinggi

2. Berdasarkan hasil penelitian menunjukan bahwa tidak terdapat perbedaan perilaku phubbing pada dewasa awal dalam situasi hubungan keluarga, hubungan pertemanan dan hubungan percintaan di Kota Bukittinggi.

\section{Saran}

Berdasarkan hasil yang diperoleh dari penelitian yang telah dilakukan, beberapa saran yang dapat dipertimbangkan sebagai berikut:

1. Secara Teoritis

Hasil penelitian ini diharapkan dapat memperkaya ilmu pengetahuan psikologi, khususnya penelitian terkait perilaku phubbing dalam situasi hubungan keluarga, hubungan pertemanan dan hubungan percintaan.

2. Secara Praktis

a. Bagi Subjek Penelitian

Bagi dewasa awal agar dapat menggunakan telepon genggam secara lebih bijak dan agar lebih meningkatkan interaksi dengan keluarga, teman, dan pasangan sehingga kualitas hubungan dapat terjaga.

b. Bagi Peneliti Selanjutnya

Untuk peneliti selanjutnya apabila berminat dengan pokok pembahasan yang sama agar menggunakan teknik pengumpulan data dan analisis data yang berbeda yang mana hal ini sebagai salah satu cara untuk lebih memahami bagaimana hubungan dalam situasi keluarga, pertemanan, dan percintaan mereka. Bagi peneliti selanjutnya agar dapat memperluas sampel penelitian pada kelompok usia yang mana dapat dilakukan dengan membandingkan antar generasi.

Kemudian untuk peneliti selanjutnya mencari sumber rujukan lebih banyak lagi terkait perilaku phubbing, terkhusus phubbing dalam situasi hubungan keluarga, hubungan pertemanan dan hubungan percintaan.

\section{Daftar Pustaka}

Afifiyah, S. (2018). Fenomena Phubbing Resahkan Masyarakat Dunia, Dampak Bodoh Telepon Pintar. Retrieved from https://www.tagar.id/fenomena-phubbing-resahkan-masyarakat-duniadampak-bodoh-telepon-pintar

Al-Saggaf, Y., \& Macculloch, R. (2019). Phubbing and Social Relationships: Results from an Australian Sample. Journal of Relationships Research. https://doi.org/10.1017/jrr.2019.9

APJII. (2019). Penetrasi \& Profil Perilaku Pengguna Internet Indonesia. Apjii, 51. Retrieved from www.apjii.or.id

Azwar, S. (2012). Penyusunan Skala Psikologi (II). Yogyakarta: Pustaka Pelajar.

Chotpitayasunondh, V., \& Douglas, K. M. (2016). How "Phubbing" Becomes The Norm: The Antecedents And Consequences Of Snubbing Via Smartphone. Computers in Human Behavior, 63, 9-18. https://doi.org/10.1016/j.chb.2016.05.018

Chotpitayasunondh, V., \& Douglas, K. M. (2018). Measuring Phone Snubbing Behavior : Development 
and Validation of the. Computers in Human Behavior, (June). https://doi.org/10.1016/j.chb.2018.06.020

David, M. E., \& Roberts, J. A. (2017). Phubbed and Alone: Phone Snubbing, Social Exclusion, and Attachment to Social Media. Journal of the Association for Consumer Research, 2(2), 155-163. https://doi.org/10.1086/690940

Jihan, A. (2019). Pengaruh Faktor Kepribadian Terhadap Phubbing Pada Generasi Milenial Di Sumatra Barat. Universitas Negeri Padang.

Karadag, E., Tosuntas, S. B., Erzen, E., Duru, P., Bostan, N., Sahin, B. M., ... Babadag, B. (2015). Determinants of Phubbing, Which is The Sum of Many Virtual Addictions : A Structural Equation Model. Journal of Behavioral Addictions, 4(2), 60-74. https://doi.org/10.1556/2006.4.2015.005

Karadağ, E., Tosuntaş, Ş. B., Erzen, E., Duru, P., Bostan, N., Şahin, B. M., ... Babadağ, B. (2016). The Virtual World's Current Addiction: Phubbing. Addicta: The Turkish Journal On Addictions, 3(2), 250-269. https://doi.org/10.15805/addicta.2016.3.0013

Krasnova, H., Abramova, O., Notter, I., \& Baumann, A. (2016). Why Phubbing is Toxic for Your Relationship: Understanding the Role Of Smartphone Jealousy among "Generation Y" Users. 24th European Conference on Information Systems, ECIS, (June).

Lestari, I., Riana, A. W., \& Taftazani, B. M. (2015). Pengaruh Gadget Pada Interaksi Sosial Dalam Keluarga. Prosiding Penelitian Dan Pengabdian Kepada Masyarakat, 2(2), 147-300. https://doi.org/10.24198/jppm.v2i2.13280

Mulyati, T., \& NRH, F. (2018). Kecanduan Smartphone Ditinjau Dari Kontrol Diri Dan Jenis Kelamin Pada Siswa Sma Mardisiswa Semarang. Empati, 7(4), 152-161.

Oduor, E., Neustaedter, C., Odom, W., Tang, A., Moallem, N., Tory, M., \& Irani, P. (2016). The Frustrations and Benefits of Mobile Device Usage in the Home when Co-Present with Family Members. DIS 2016 - Proceedings of the 2016 ACM Conference on Designing Interactive Systems: Fuse, 1315-1327. https://doi.org/10.1145/2901790.2901809

Papalia, D. E., Old, S. wendkos, \& Feldman, R. D. (2011). Human Development (Psikologi Perkembangan) (Ed.9 Cet.2). Jakarta: Kencana.

Roberts, J. A., \& David, M. E. (2016). My Life Has Become a Major Distraction From My Cell Phone: Partner Phubbing and Relationship Satisfaction Among Romantic Partners. Computers in Human Behavior, 54, 134-141. https://doi.org/10.1016/j.chb.2015.07.058

Sugiyono. (2013). Metode Penelitian Kuantitatif, Kualitatif, dan R\&B. Bandung: Alfabeta.

Sulis, H. (2016). Gara-gara Ponsel Pintar, Pertemanan Rusak Hubungan Cinta Bubar. Retrieved from https://lampung.tribunnews.com/2016/07/12/gara-gara-ponsel-pintar-pertemanan-rusakhubungan-cinta-bubar

Thaeras, F. (2017). "Phubbing", Fenomena Sosial yang Merusak Hubungan. Retrieved from https://www.cnnindonesia.com/gaya-hidup/20170714134144-277-227920/phubbingfenomena-sosial-yang-merusak-hubungan 
Perbedaan Perilaku Phubbing Pada Dewasa Awal dalam Situasi Hubungan Keluarga, Hubungan Pertemanan, dan Hubungan Percintaan Di Kota Bukittinggi

Proyeksi Vol. 15 (2) 2020, 141-150

Vanden Abeele, M. M. P., Hendrickson, A. T., Pollmann, M. M. H., \& Ling, R. (2019). Phubbing Behavior In Conversations and Its Relation to Perceived Conversation Intimacy and Distraction: An Exploratory Observation Study. Computers in Human Behavior, 100, 35-47. https://doi.org/10.1016/j.chb.2019.06.004

Winarsunu, T. (2007). Statistik dalam Penelitian Psikologi dan Pendidikan (1st ed.). Malang: UMM Press.

Youarti, I. E., \& Hidayah, N. (2018). Perilaku Phubbing Sebagai Karakter Remaja Generasi Z. Jurnal Fokus Konseling, 4(1), 143-152. 